\title{
Employment and risk of injection drug use initiation among street involved youth in Canadian setting
}

\author{
Lindsey Richardson ${ }^{\mathrm{a}, \mathrm{b}}$, Kora DeBeck ${ }^{\mathrm{a}, \mathrm{c}}$, Cindy Feng ${ }^{\mathrm{a}, \mathrm{d}}$, Thomas Kerr ${ }^{\mathrm{a}, \mathrm{b}}$, and Evan Wood ${ }^{\mathrm{a}, \mathrm{b}}$ \\ aBritish Columbia Centre for Excellence in HIV/AIDS, St. Paul's Hospital, 608-1081 Burrard \\ Street, Vancouver, BC, Canada, V6Z 1Y6 \\ ${ }^{b}$ Faculty of Medicine, University of British Columbia, Room 10203 - 2775 Laurel St., Vancouver, \\ BC, Canada V5Z $1 \mathrm{M} 9$ \\ 'School of Public Policy, Simon Fraser University, SFU Harbour Centre, 515 West Hastings \\ Street, Suite 3271, Vancouver, BC, Canada V6B 5K3 \\ dSchool of Public Health, University of Saskatchewan, Room 3338, Health Sciences Building E- \\ Wing, 104 Clinic Place, University of Saskatchewan, Saskatoon SK S7N 5E5
}

\begin{abstract}
Objective-Youth unemployment has been associated with labour market and health disparities. However, employment as a determinant of high-risk health behaviour among marginalized young people has not been well described. We sought to assess a potential relationship between employment status and initiation of intravenous drug use among a prospective cohort of streetinvolved youth.
\end{abstract}

Method-We followed injecting naïve youth in the At-Risk Youth Study, a cohort of streetinvolved youth aged 14-26 in Vancouver, Canada, and employed Cox regression analyses to examine whether employment was associated with injection initiation.

Results-Among 422 injecting naïve youth recruited between September 2005 and November 2011, 77 participants transitioned from non-injection to injection drug use, for an incidence density of 10.3 (95\% confidence interval [CI]: 8.0-12.6) per 100 person years. Results demonstrating that employment was inversely associated with injection initiation (adjusted hazard ratio: 0.53 ; $95 \%$ CI: $0.33-0.85$ ) were robust to adjustment for a range of potential confounders.

(C) 2014 Elsevier Inc. All rights reserved.

Send correspondence to: Evan Wood, BC Centre for Excellence in HIV/AIDS, Department of Medicine, University of British Columbia, 608-1081 Burrard Street, Vancouver, B.C. V6Z 1Y6, CANADA, Tel: (604) 806-9116, Fax: (604) 806-9044, uhriew@cfenet.ubc.ca.

Contributors

CF performed the statistical analyses. LR drafted the initial manuscript. EW, KD, and TK performed significant revisions to the manuscript. All authors made significant contributions to the conception and design of the analyses, interpretation of the data, and approved the final version of the manuscript.

Conflict of Interest

All authors declare they have no conflicts of interest.

Publisher's Disclaimer: This is a PDF file of an unedited manuscript that has been accepted for publication. As a service to our customers we are providing this early version of the manuscript. The manuscript will undergo copyediting, typesetting, and review of the resulting proof before it is published in its final citable form. Please note that during the production process errors may be discovered which could affect the content, and all legal disclaimers that apply to the journal pertain. 
Conclusion-A lack of employment among street-involved youth was associated with the initiation of injection drug use, a practice that predisposes individuals to serious long-term health consequences. Future research should examine if reducing barriers to labour market involvement among street-involved youth prevents transitions into high-risk drug use.

\section{Keywords}

injection initiation; street-involved youth; injection drug use; youth unemployment

\section{Introduction}

Suboptimal labour market involvement among youth negatively impacts long-term labour market trajectories and future health disparities. Youth unemployment has been shown to produce enduring wage penalties (Gregg and Tominey, 2005); negative psychological, substance use-related and somatic health outcomes; as well as increased health risk behaviour (Reine et al., 2013; Henkel, 2011; Dooley et al., 1996; Hammarström and Janlert, 2002). However, the impacts of suboptimal labour market outcomes on health risk behaviours among marginalized youth, as a group facing potentially elevated barriers to employment and susceptibility to health risk, have not been fully described. Specifically, to our knowledge very little is known about the degree to which employment prevents transitions to high-risk behaviours among this population. We therefore examined the relationship between employment status and the initiation of injection drug use among a cohort of street-involved youth in Vancouver, Canada.

\section{Data and Methods}

The current study uses data derived from the At-Risk Youth Study (ARYS), an ongoing, prospective cohort study of street-involved youth in Vancouver, Canada (Wood et al., 2008) seeking to examine the health harms of drug use among street-involved youth with a specific focus on initiation into injection. Eligible individuals between 14 and 26 years of age who had used illicit drugs other than or in addition to cannabis in the previous 30 days and provided written informed consent were recruited into the study beginning in September 2005. At baseline and semi-annually on an on-going basis thereafter, participants receive a $\$ 30$ (CAD) honorarium for each study visit, during which they complete a detailed interviewer-administered questionnaire verified for use in the current study context that collects sociodemographic information as well as detailed data about drug use patterns, associated risk exposures, and income sources. Participants are also examined for stigmata of intravenous drug injecting and provide a blood sample for analysis. ARYS has been approved by the University of British Columbia/Providence Health Care Research Ethics Review Board.

Of the 991 street-involved youth recruited into ARYS between September 2005 and November 2011, the current study was restricted to 422 individuals who had never injected at baseline and completed at least one study follow-up. This excluded 390 (39.3\%) participants who report injecting at baseline and $179(18.1 \%)$ participants who did not inject at baseline but who did not have a follow-up visit. All observations contributed by eligible participants were included in analyses. The outcome of interest, initiation of injection, was 
observed if during the portion of the questionnaire pertaining to drug use activity, a participant responded affirmatively to the question "In the last 6 months, have you used a needle to chip, fix or muscle, even once?" The primary covariate of interest was a timeupdated, binary indicator of employment, defined as having a regular job, self-employment or temporary work as a source of income in the six months prior to interview.

We also considered a range of potential confounders, including sociodemographic variables, such as age (per year older), gender (female vs. male) and ethnicity (Caucasian vs. other); and measures of substance use including high-intensity alcohol or marijuana use ( $\geq$ daily vs. $<$ daily) as well as non-injection cocaine, crack-cocaine, crystal methamphetamine and heroin use (yes vs. no) in the six months prior to interview. Time-updated drug use variables were lagged to the previous six-month period to account for the possibility of reverse causality.

We first calculated the incidence density of injection initiation using person time methods. We then examined baseline characteristics of the sample stratified by injection initiation over the study period using Pearson's Chi-square test for dichotomous variables and the Wilcoxon rank sum test for continuous variables. We subsequently calculated the cumulative hazard of injection initiation from the time of study enrollment stratified by a time-updated measure of employment status using Kaplan-Meier methods. Finally, using an a priori multivariate model building protocol (Maldonado and Greenland, 1993; Rothman and Greenland, 1998), we formulated a series of Cox proportional hazards regression analyses. Following univariate analyses, we constructed a full model including all variables. We then developed a reduced model using a manual stepwise procedure whereby each iteration excluded the covariate from the previous model that produced the smallest relative change in the employment coefficient until the minimum change exceeded five per cent. All variables that modified the employment coefficient by greater than five percent relative to that of the full model were therefore included in the final multivariate confounding model. This strategy retains those covariates with greater relevance to the association between the outcome and primary covariate of interest (Lima et al., 2009; Milloy et al., 2011). Statistical analyses were performed using SAS 9.2 (SAS, Cary, NC, USA). Tests of significance were two sided with the minimum threshold for significance set to $p<0.05$.

\section{Results}

The present study included the baseline and follow-up observations of 422 street-involved youth enrolled between December 2005 and November 2011 who were followed for a median of follow-up time of 20.6 months (interquartile range $=12.6-26.1$ ). Sample baseline characteristics are described in Table 1. Two hundred fifty-four (60.1\%) participants reported holding regular, self- or temporary employment in the six months prior to baseline interview and $340(80.6 \%)$ participants reported employment over the study period. Seventy-seven (18.2\%) individuals reported injection initiation for an incidence density of 10.3 (95\% confidence interval [CI]: 7.98-12.58) per 100 person years, with the cumulative incidence of injection initiation (Figure 1) among non-employed participants (46.0\%) being significantly greater than that of employed participants (23.8\%) after 50 months (log rank $p$ $=0.004)$. 
Results from the univariate and multivariate Cox proportional hazard analyses (Table 1) show that self-reported regular or temporary employment was significantly and negatively associated with an increased risk of initiating injection drug use in both univariate (hazard ratio $[\mathrm{HR}]=0.50,95 \% \mathrm{CI}: 0.31-0.81$ ) and multivariate (adjusted $\mathrm{HR}=0.53,95 \%$ CI: 0.33 $-0.85)$ analyses. These findings were robust to adjustment for potential confounders, including non-injection crystal methamphetamine use $(p=0.027)$ and heroin use $(p=0.089)$ in the follow-up period preceding injection initiation.

\section{Discussion}

This longitudinal study of street-involved youth in Vancouver, Canada identifies an inverse association between self-reported employment and initiating injection drug use after adjustment for potential confounders. These findings are consistent with previous literature identifying increases in health risk behaviours among unemployed youth (Dooley et al., 1996; Hammarström and Janlert, 2002; Henkel, 2011). This study additionally reinforces the importance of social and institutional ties in the prevention of suboptimal health outcomes among high-risk youth (Carver and Scheier, 1982; Small et al., 2009; Viner et al., 2012). However, to our knowledge this study is the first to isolate the potential role of employment in preventing the initiation of a drug administration practice that has specific and significant implications for the prevention of drug injection-related harm, including elevated morbidity and mortality related to the transmission of HIV and hepatitis C, and overdose (Mathers et al., 2008; Nelson et al., 2011; Degenhardt et al., 2011). Preventing the initiation or intensification of high-risk drug use practices therefore represents an additional and potentially important rationale for policy and programmatic initiatives seeking to decrease youth unemployment (Viner et al., 2012), particularly among marginalized youth.

A number of limitations common to observational cohort studies apply to the current analysis. As the study population is not a random sample findings may not be generalizable to other populations of street-involved youth. Additionally, study data are based on selfreport and may be subject to response bias including recall and social desirability biases, though we know of no reason why youth at risk of initiating injecting would preferentially report higher rates of unemployment. Finally, the relationship between employment and injection initiation may be influenced by variables, such as mental illness or other potential confounders, not examined as part of the ARYS study.

In conclusion, this study reports a previously unidentified inverse association between employment and injection initiation among street-involved youth. The employment of vulnerable young people may therefore mitigate the initiation of high-risk drug use practices. While the problems resulting from youth unemployment are widely acknowledged, these results emphasize the potentially significant health impacts of the economic marginalization of street-involved youth, which warrant specific consideration in efforts to promote the adequate and appropriate involvement of young people in the labour market. 


\section{Acknowledgments}

The authors thank the study participants for their contribution to the research, as well as current and past researchers and staff. We would specifically like to thank Deborah Graham, Steve Kain and Cody Callon for their research and administrative assistance. The study was supported by the US National Institutes of Health (R01DA028532) and the Canadian Institutes of Health Research (MOP-102742). This research was undertaken, in part, thanks to funding from the Canada Research Chairs program through a Tier 1 Canada Research Chair in Inner City Medicine which supports Dr. Evan Wood. Dr. Richardson holds Canadian Institutes of Health Research postdoctoral fellowship. Dr. Kora DeBeck is supported by a MSFHR/St. Paul's Hospital-Providence Health Care Career Scholar Award.

Role of Funding Source

This study was supported by the US National Institutes of Health (R01DA028532) and the Canadian Institutes of Health Research (MOP-102742). These funding sources had no further role in study design; in the collection, analysis and interpretation of data; in the writing of the report; or in the decision to submit the paper for publication

\section{References}

Carver CS, Scheier MF. Control theory: a useful conceptual framework for personality-social, clinical, and health psychology. Psychol Bull. 1982; 92(1):111-35. [PubMed: 7134324]

Degenhardt L, Bucello C, Mathers B, Briegleb C, Ali H, Hickman M, McLaren J. Mortality among regular or dependent users of heroin and other opioids: a systematic review and meta-analysis of cohort studies. Addiction. 2011; 106(1):32-51. [PubMed: 21054613]

Dooley D, Fielding J, Levi L. Health and unemployment. Annu Rev Publ Health. 1996; 17(1):449-65.

Gregg P, Tominey E. The wage scar from male youth unemployment. Labour Econ. 2005; 12(4):487509.

Hammarström A, Janlert U. Early unemployment can contribute to adult health problems: results from a longitudinal study of school leavers. J Epidemiol Commun H. 2002; 56(8):624-30.

Henkel D. Unemployment and substance use: a review of the literature (1990-2010). Curr Drug Abuse Rev. 2011; 4(1):4-27. [PubMed: 21466502]

Lima V, Fernandes K, Rachlis B, Druyts E, Montaner J, Hogg R. Migration adversely affects antiretroviral adherence in a population-based cohort of HIV/AIDS patients. Soc Sci Med. 2009; 68(6):1044-9. [PubMed: 19157668]

Maldonado G, Greenland S. Simulation study of confounder-selection strategies. Am J Epidemiol. 1993; 138(11):923-36. [PubMed: 8256780]

Mathers BM, Degenhardt L, Phillips B, Wiessing L, Hickman M, Strathdee SA, Wodak A, Panda S, Tyndall M, Toufik A, Mattick RP. Reference Group to the UN on HIV and Injecting Drug Use, 2008, Global epidemiology of injecting drug use and HIV among people who inject drugs: a systematic review. Lancet. 2007; 372(9651):1733-45. [PubMed: 18817968]

Milloy MJ, Kerr T, Buxton J, Rhodes T, Guillemi S, Hogg R, Montaner J, Wood E. Dose-response effect of incarceration events on nonadherence to HIV antiretroviral therapy among injection drug users. J Infect Dis. 2011; 203(9):1215-21. [PubMed: 21459814]

Nelson PK, Mathers BM, Cowie B, Hagan H, Des Jarlais D, Horyniak D, Degenhardt L. Global epidemiology of hepatitis B and hepatitis $\mathrm{C}$ in people who inject drugs: results of systematic reviews. Lancet. 2011; 378(9791):571-83. [PubMed: 21802134]

Reine I, Novo M, Hammarström A. Unemployment and ill health--a gender analysis: results from a 14-year follow-up of the Northern Swedish Cohort. Public Health. 2013; 127(3):214-22. [PubMed: 23375366]

Rothman, KJ.; Greenland, S. Lippincott Williams and Wilkins; New York: 1998.

Small W, Fast D, Krusi A, Wood E, Kerr T. Social influences upon injection initiation among streetinvolved youth in Vancouver, Canada: a qualitative study. Subst Abuse Treat Prev Policy. 2009; 4:8. [PubMed: 19405977]

Viner RM, Ozer EM, Denny S, Marmot M, Resnick M, Fatusi A, Currie C. Adolescence and the social determinants of health. Lancet. 2012; 379(9826):1641-52. [PubMed: 22538179] 
Wood E, Stoltz JA, Zhang R, Strathdee SA, Montaner JS, Kerr T. Circumstances of first crystal methamphetamine use and initiation of injection drug use among high-risk youth. Drug Alcohol Rev. 2008; 27(3):270-6. [PubMed: 18368608] 


\section{Highlights}

- This study examined employment and injection initiation among street-involved youth

- Results identified an independent inverse association between work and initiation

- Employment may prevent key transitions to high-risk drug use practices among youth

- Findings are specifically relevant to the prevention of injection related harm

- Decreasing unemployment among youth may provide significant health benefits 


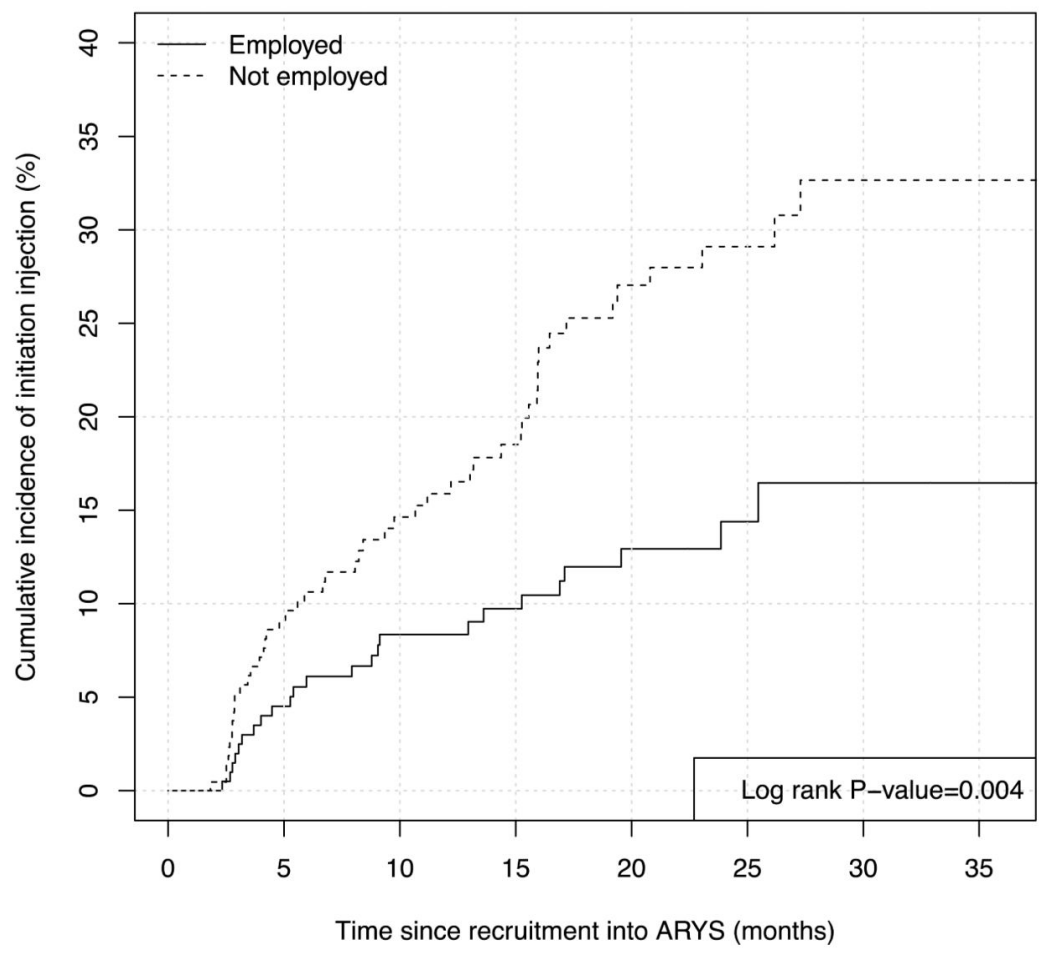

Figure 1.

Cumulative incidence of injection initiation among street-involved youth stratified by employment status in Vancouver, Canada, 2005-2011 ( $\mathrm{n}=422)$ 


\section{Table 1}

Baseline characteristics of injection-naive youth who did and who did not initiate injection drug use and unadjusted and adjusted hazard ratios for factors associated with injection drug use initiation among streetinvolved youth in Vancouver, Canada, 2005-2011 ( $\mathrm{n}=422)$.

\begin{tabular}{|c|c|c|c|c|}
\hline \multirow{3}{*}{ Characteristic } & \multirow{2}{*}{\multicolumn{2}{|c|}{$\begin{array}{c}\text { Baseline characteristics } \\
\text { Injection initiation }\end{array}$}} & \multicolumn{2}{|c|}{$\begin{array}{c}\text { Univariate and multivariate Cox regression } \\
\text { analysis }\end{array}$} \\
\hline & & & \multirow{2}{*}{$\begin{array}{l}\text { Unadjusted HR } \\
\quad(95 \% \text { CI })\end{array}$} & \multirow{2}{*}{$\begin{array}{l}\text { Adjusted HR } \\
(\mathbf{9 5 \%} \text { CI })\end{array}$} \\
\hline & $\begin{array}{l}\text { Yes }(\mathbf{n}=77) \\
\mathbf{n}(\%)\end{array}$ & $\begin{array}{l}\text { No }(\mathbf{n}=345) \\
\quad n(\%)\end{array}$ & & \\
\hline \multicolumn{5}{|l|}{ Employment $^{a}$} \\
\hline Yes & $34(44.2)$ & $220(63.8)$ & $0.50(0.31-0.81)$ & $0.53(0.33-0.85)$ \\
\hline No & $43(55.8)$ & $125(36.2)$ & & \\
\hline Age (per year older) & $21.3(19.6,22.5)$ & $21.6(19.6,23.3)$ & $0.96(0.88-1.04)$ & \\
\hline \multicolumn{5}{|l|}{ Caucasian ethnicity } \\
\hline Yes & $54(70.1)$ & $204(59.1)$ & $1.50(0.92-2.44)$ & \\
\hline No & $23(29.9)$ & $141(40.9)$ & & \\
\hline \multicolumn{5}{|l|}{ Female gender } \\
\hline Yes & $23(29.9)$ & $110(31.9)$ & $0.98(0.60-1.60)$ & \\
\hline No & $54(70.1)$ & $235(68.1)$ & & \\
\hline \multicolumn{5}{|c|}{ Non-Injection Crystal Meth Use ${ }^{a, b}$} \\
\hline Yes & $41(53.2)$ & $107(31.0)$ & $1.83(1.16-2.87)$ & $0.68(1.06-2.65)$ \\
\hline No & $36(46.8)$ & $238(69.0)$ & & \\
\hline \multicolumn{5}{|c|}{ Non-Injection Cocaine Use ${ }^{a, b}$} \\
\hline Yes & $31(40.3)$ & $175(50.7)$ & $0.99(0.62-1.57)$ & \\
\hline No & $46(59.7)$ & $170(49.3)$ & & \\
\hline \multicolumn{5}{|c|}{ Crack Cocaine Smoking ${ }^{a, b}$} \\
\hline Yes & $52(67.5)$ & $184(53.3)$ & $1.38(0.88-2.18)$ & \\
\hline No & $25(32.5)$ & $161(46.7)$ & & \\
\hline \multicolumn{5}{|c|}{ Non-Injection Heroin Use ${ }^{a, b}$} \\
\hline Yes & $18(23.4 \%)$ & $48(13.9)$ & $1.83(1.06-3.14)$ & $1.61(0.93-2.78)$ \\
\hline No & $59(76.6 \%)$ & $297(86.1)$ & & \\
\hline \multicolumn{5}{|c|}{ Daily Marijuana Use ${ }^{a, b}$} \\
\hline Yes & $64(83.1)$ & $316(91.6)$ & $0.99(0.58-1.80)$ & \\
\hline No & $13(16.9)$ & $29(8.4)$ & & \\
\hline \multicolumn{5}{|l|}{ Daily Alcohol Use ${ }^{a, b}$} \\
\hline Yes & $14(18.2)$ & $59(17.1)$ & $0.99(0.55-1.80)$ & \\
\hline No & $63(81.8)$ & $286(82.9)$ & & \\
\hline
\end{tabular}

HR: hazard ratio; CI: confidence interval

$a_{\text {denotes activities in the six months prior to follow-up interview }}$ 
${ }^{b}$ refers to the activities lagged to the previous available follow-up 